\title{
FRACTIONAL LYAPUNOV INEQUALITIES ON SPHERICAL SHELLS
}

\author{
YousEF GHOLAMI AND KAZEM GHANBARI
}

\begin{abstract}
This paper, deals with Lyapunov inequalities of conformable fractional boundary value problems on an N-dimensional spherical shell. Applicability of these Lyapunov inequalities will be examined by establishing the disconjugacy as a nonexistence criterion for nontrivial solutions, lower bound estimation for eigenvalues of the corresponding fractional eigenvalue problem, upper bound estimation for maximum number of zeros of the nontrivial solutions and distance between consecutive zeros of an oscillatory solution.
\end{abstract}

Mathematics subject classification (2010): 34A08, 26A33, 26D15.

Keywords and phrases: Conformable fractional derivative, Lyapunov inequality, Spherical shell, Qualitative dynamic.

\section{REFERENCES}

[1] T. Abdeljawad, On conformable fractional calculus, J. Comput. Appl. Math. 279 (2015), 57-66.

[2] George A. Anastassiou, Multivariate Lyapunov inequalities, Appl. Math. Lett., 24 (2011), 2167 2171.

[3] George A. Anastassiou, Advances on Fractional Inequalities, Springer, 2011.

[4] A. Chidoun, D. F. M. Torres, A generalized Lyapunov's inequality for a fractional boundary value problem, J. Comput. Appl. Math. 312, 1 (2017), 192-197.

[5] RUi A.C. Ferreira, A Lyapunov-type inequality for a fractional boundary value problem, Fract. Calc. Appl. Anal. 16, 4 (2013), 978-984. DOI: 10.2478/s13540-013-0060-5.

[6] Sougata DHAR, QIngKai Kong, Liapunov-type inequalities for third-order half-linear equations and applications to boundary value problems, Nonlinear Anal. Theory, Methods and Applications 110 (2014), 170-181.

[7] S. Dhar, Q. Kong, M. MCCABE, Fractional boundary value problems and Lyapunov-type inequalities with fractional integral boundary conditions, Electron. J. Qual. Theory Differ. Equ. 43 (2016), $1-16$.

[8] RUi A. C. FERreira, On a Lyapunov-type inequality and the zeros of a certain Mittag-Leffler function, J. Math. Anal. Appl., 412 (2014), 1058-1063.

[9] Rui A. C. Ferreira, Some discrete fractional Lyapunov-type inequalities, Fractional. Differ. Calc, 5, 1 (2015), 87-92.

[10] Rui A. C. Ferreira, Lyapunov-type inequalities for some sequential fractional boundary value problems, Adv. Dyn. Syst. Appl. 11, 1 (2016), 33-43.

[11] Kazem Ghanbari, Yousef Gholami, Applications of Lyapunov type inequalities for fractional Sturm-Liouville problems and fractional Hamiltonian systems, Journal of Fractional Calculus and Applications, 7, 1 (2016), 176-188.

[12] KaZem Ghanbari, Yousef Gholami, New classes of Lyapunov type inequalities of fractional $\Delta$-difference Sturm-Liouville problems with applications, Bull. Iranian Math. Soc. 43, 2 (2017), 385408.

[13] P. Hartman, Ordinary Differential Equations, John Wiley and Sons, New York, 1964.

[14] Udita N. Katugampola, Correction to "What is a fractional derivative?" by Ortigueira and Machado [Journal of Computational Physics, Volume 293, 15 July 2015, Pages 4-13. Special issue on Fractional PDEs], J. Comput. Phys., 321, (2016), 1255-1257.

[15] R. Khalil, M. Al Horani, A. Yousef, M. Sababheh, A new definition of fractional derivative, J. Comput. Appl. Math. 264 (2014), 65-70. 
[16] A. A. Kilbas, H. M. SRivastava, J. J. Trujillo, Theory and Applications of Fractional Differential Equations, North-Holland mathematics studies, Elsevier science, 204, 2006.

[17] A. M. Liapunov, The general problem of the stability of motion, Int. J. Control 55, 3 (1992), $521-$ 790. http://www.tandfonline.com/toc/tcon20/55/3.

[18] K. S. MiLler, B. Ross, An Introduction to fractional calculus and fractional differential equation, John Wiley, New York, 1993.

[19] K. B. Oldham, J. Spanier, The fractional calculus, Academic Press, New York, 1974.

[20] D. O'REGAN, B. SAMET, Lyapunov-type inequalities for a class of fractional differential equations, J. Inequal. Appl. (2015), 2015:247.

[21] M. D. Ortigueira, J. A. Tenreiro Machadob, What is a fractional derivative?, J. Comput. Phys. 293 (2015), 4-13.

[22] I. Podlubny, Fractional Differential Equations, Mathematics in Science and Applications, Academic Press, New York, 19, 1999.

[23] J. Rong, C. BAI, Lyapunov-type inequality for a fractional differential equation with fractional boundary conditions, Adv. Difference Equ. (2015), 2015:82 DOI 10.1186/s13662-015-0430-x.

[24] W. Rudin, Real and Complex Analysis, McGraw-Hill, New York, 1970.

[25] VAsily E. TARASOv, No violation of the Leibniz rule. No fractional derivative, Commun. Nonlinear Sci. Numer. Simul. 18, 11 (2013), 2945-2948.

[26] Vasily E. Tarasov, On chain rule for fractional derivatives, Commun. Nonlinear Sci. Numer. Simul. 30 (2016), $1-4$. 